Note: this is a post-print draft of the journal article:

3

4 Dressler, M. R., M. A. Strickland, et al. (2011). "Predicting wear of UHMWPE: Decreasing wear 5 rate following a change in direction." Wear 271(11-12): 2879-2883.

6

7 The final, fully proofed and peer-reviewed journal article is available from the publisher online, 8 via the following links:

9

10

http://dx.doi.org/10.1016/j.wear.2011.06.006

11

12

http://www.sciencedirect.com/science/article/pii/S0043164811004467 


\section{Predicting Wear of UHMWPE: Decreasing Wear Rate Following a Change in Direction}

Matthew R Dressler ${ }^{1}$, Michael A Strickland ${ }^{2}$, Mark Taylor ${ }^{2}$, Todd D Render $^{1}$, Craig N Ernsberger $^{1}$

${ }^{1}$ DePuy Orthopaedics 700 Orthopaedic Drive

Warsaw, IN 46581

\author{
${ }^{2}$ Bioengineering Sciences Research Group, \\ School of Engineering Sciences \\ University of Southampton \\ Hampshire, SO17 1BJ (UK)
}

Corresponding author address:

Matthew R. Dressler

DePuy Orthopaedics

700 Orthopaedic Drive

Warsaw, IN 46581

mdressle@its.jnj.com

Coauthor Email Addresses:

MAS: ams05@alumni.soton.ac.uk

MT: m.taylor@soton.ac.uk

TDR: trender@its.jnj.com

CNE: cernsber@its.jnj.com 


\section{Abstract (200 words)}

1 Computational tools are emerging as design tools for the development of total joint replacement with

2 improved wear performance. The current wear models of polyethylene assume that wear is linearly

3 proportional to sliding distance; however, it is hypothesised that the wear rate varies and is higher near

4 a change in direction, but diminishes with continued unidirectional sliding, which eventually exhibits

5 negligible wear. Our goals were to (1) reveal the presence of a variable wear rate in polyethylene (2)

6 identify the sliding distance required to reestablish unidirectional sliding subsequent to a change in

7 sliding direction. The wear of polyethylene was evaluated in pin-on-disk testing for several different

8 sliding distances $(0 \mathrm{~mm}, 1 \mathrm{~mm}, 2 \mathrm{~mm}, 5 \mathrm{~mm}, 10 \mathrm{~mm}, 100 \mathrm{~mm})$ after a $90^{\circ}$ change in direction. The results

9 indicate the wear rate immediately following the change in direction is high, but with continued linear

10 sliding the wear rate appears to drop to near zero-returning to the low wearing condition of

11 unidirectional sliding. Furthermore, this transition appears to occur nonlinearly below $5 \mathrm{~mm}$ from the

12 change in direction. While more studies are required to explore other paths and uncover the underlying

13 mechanisms, these results should aid the development of computational tools for the design of

14 advanced joint replacement.

\section{Keywords}

16 Bio-tribology; joint prostheses; Wear testing; Polymers; Non-ferrous metals; Sliding wear; Wear

17 modelling 


\section{Introduction}

1 Osteoarthritis, manifest by a loss of the articular cartilage that lines the bone of synovial joints, can

result in pain that limits activities of daily living. It is estimated that $10 \%$ of the global population age 60 years and older experiences significant clinical problems due to osteoarthritis [1]. Total joint replacement has emerged as the standard treatment for advanced osteoarthritis achieving greater than $90 \%$ survivorship after 15 years or more [2,3]. Not surprisingly with this long-term clinical success, the frequency of this procedure has increased substantially in the United States and is expected to grow exponentially in the next decades [4, 5]. In addition to the growing numbers of patients, expectations are growing with many younger and active patients expecting to return to their previous lifestyle after surgery [6-9], enjoying activities such as cycling, hiking, tennis, etc [7]. Consequently, new products are emerging that have been designed to meet these increased performance demands.

In vitro wear simulations are often used to benchmark the wear performance of new products against clinically successful predicate devices. While invaluable, these in vitro tests are long, expensive, and can only be performed near the end of the design cycle. Computational modeling (both finite element and rigid body modeling) techniques have the potential to acquire insights into the wear behavior of new designs faster, cheaper, and earlier in the design process. Early studies, implementing Archard's law, reported reasonable correlations with implant retrievals [10] and experimental data [11]. However, a more extensive study comparing multiple implant designs and kinematic conditions achieves good correlation with in vitro wear results $\left(R^{2} \approx 0.6\right)$, restricting its use to qualitative comparisons rather than absolute quantitative wear values [12].

Further improvements in the predictive power of in silico wear simulation could be achieved by revisiting and refining the underlying wear model for ultrahigh molecular weight polyethylene (UHMWPE). The classic Archard relationship for abrasive wear, where wear is proportional to the contact pressure and the sliding distance [13], established a foundation for many computational studies in total joint replacement [14-17]. Further investigations into the fundamental wear behavior revealed accelerated wear of polyethylene when articulated with so called crossing motions as compared to linear reciprocation [18-21]. Consequently, a cross-shear term was introduced to augment the original Archard relationship [19, 22, 23]. This greatly improved predictive power [12, 24], but as mentioned previously, these models are best reserved for qualitative comparisons. Although there are several different cross-shear formulations, most are calculated post-hoc from the aggregate motion rather than determined at each step in time from a time history of sliding events.

For example, square articulation paths will produce similar cross-shear regardless of their size and therefore the cumulative wear of square paths are solely dependent on the total sliding distance. This scale-independence assumes, perhaps erroneously, a constant wear rate along the sliding path. While the instantaneous wear rate in a region subsequent to a change in direction will be high, it is possible that a very large square will possess sides so long that the instantaneous wear rate will eventually drop to near zero similar to the behavior in unidirectional sliding (Figure 1). To the authors' knowledge, this variation in wear rate with sliding distance after a change in sliding direction has not been explored experimentally. 
Using a novel experimental design for pin-on-disk testing, we combined reciprocating linear sliding with $90^{\circ}$ rotations to investigate the fundamental wear behavior of two commercially available crosslinked polyethylenes used in orthopaedic joint replacement. Specifically our goals were to (1) reveal the presence of a variable wear rate; (2) identify the sliding distance required to reestablish unidirectional sliding subsequent to a change in sliding direction.

\section{Methods}

1 Wear was evaluated for similar articulation paths having six different sliding distances $(0 \mathrm{~mm}, 1 \mathrm{~mm}$, $22 \mathrm{~mm}, 5 \mathrm{~mm}, 10 \mathrm{~mm}, 100 \mathrm{~mm}$ ) using an OrthoPOD Wear Testing Machine (AMTI, Watertown, MA). Pins $3(\mathrm{n}=3)$ reciprocated in short segments $(0 \mathrm{~mm}, 1 \mathrm{~mm}, 2 \mathrm{~mm}$, or $5 \mathrm{~mm})$ on a broad arc (radius $=52.4 \mathrm{~mm}$ ) 4 under a $330 \mathrm{~N}$ constant vertical load ( $\sim .7 \mathrm{MPa}$ which is similar to mean pressures experienced in total 5 joint replacement $[12,14])$ and constant sliding velocity $(64 \mathrm{~mm} / \mathrm{s})$ until they achieved the target sliding 6 distance per cycle (see Figure 2 and Table 1 for summary of experimental conditions). The pins then 7 stopped translating and rotated $90^{\circ}$ about their own axis under a reduced vertical load of $30 \mathrm{~N}$ 8 ( 0.4MPa). The loading was restored to $330 \mathrm{~N}$ and sliding recommenced. A complete cycle included two sliding portions and two rotations of $\pm 90^{\circ}$. For example, in the case of the $100 \mathrm{~mm}$ path, pins reciprocated 20 times in $5 \mathrm{~mm}$ increments, rotated $90^{\circ}$, slid $100 \mathrm{~mm}$ again, and then rotated back to $0^{\circ}$.

Two different polyethylene materials were evaluated. Both were comprised of GUR 1020 resin. One group $\left(\mathrm{GVF}^{\mathrm{TM}}\right)$ was gamma irradiated to $40 \mathrm{kGy}$ in a vacuum pouch. The other group (XLK $\left.{ }^{\mathrm{TM}}\right)$ was irradiated to $50 \mathrm{kGy}$ and then remelted. The pins were machined from molded pucks to final dimensions of $17.8 \mathrm{~mm}$ (0.375 inch) diameter and $9.5 \mathrm{~mm}(0.7$ inch) length.

Each pin articulated against a mirror polished wrought Co28Cr6Mo counterface. The disks, conforming to ASTM F1537 Alloy 2 (UNS 31538), were polished to an Ra of less than 10nm. No passivation treatment was applied prior to wear testing. The disks had a diameter of $38.1 \mathrm{~mm}(1.5 \mathrm{inch})$ and were $12.7 \mathrm{~mm}(0.5$ inch) thick.

Testing was performed at $37 \pm 1{ }^{\circ} \mathrm{C}$ in $90 \%$ bovine serum (HyClone, Logan UT) supplemented with $0.2 \%$ sodium azide and $20 \mathrm{mM}$ EDTA to retard bacterial growth and calcium precipitation. The specimens articulated in the OrthoPOD for approximately 50 hours and were then removed for analysis. All pins were then cleaned and weighed (similar to current ISO and ASTM standards $[25,26]$ ) using an analytical balance (AX205, Mettler Toledo, Columbus OH). A "soak corrected wear" value was determined for each pin by summing the measured weight loss with the average weight gain of three soak specimens. $A$ linear wear rate was then calculated using a best-fit linear regression through the soak corrected data, excluding the 0 cycle wear data point. A one-way analysis of variance (ANOVA) was used with a post-hoc

27 Tukey multiple comparison tests to detect statistical differences between sliding distances within $\mathrm{XLK}^{\mathrm{TM}}$ 28 and $\mathrm{GVF}^{\mathrm{TM}}$ materials (experimentwise $\alpha=0.05$ within materials).

\section{$\underline{\text { Results }}$}

1 In general, the average wear per cycle increased as the sliding distance between turns increased, but 2 appears to plateau after 5-10mm for both $\mathrm{GVF}^{\mathrm{TM}}$ and $\mathrm{XLK}^{\mathrm{TM}}$ (Figure 3). In other words, increasing the 
3 amount of sliding between changes in direction over an order of magnitude from $5 \mathrm{~mm}$ to $100 \mathrm{~mm}$

4 produced little to no concomitant wear. The $\mathrm{GVF}^{\mathrm{TM}}$ groups wore nearly twice as much as $\mathrm{XLK}{ }^{\mathrm{TM}}$ for all

5 conditions (Figure 4).

6 Statistical analysis revealed that smaller sliding distances produce reduced wear rates in GVF. This trend 7 was similar in $X L^{T M}$, but did not reach statistical significance likely due to the large standard deviations 8 associated with the $0 \mathrm{~mm}$ and $100 \mathrm{~mm}$ groups in $X \mathrm{LK}^{\mathrm{TM}}$. If these groups are removed, differences

9 between the sliding distances emerge. This data can also be expressed 'per turn' rather than 'per cycle' 10 through scale factor of 2 given that each cycle included two turns (Figures $4 a$ and $4 b$ ).

11 When wear is normalized by sliding distance, the conditions with shorter travel between turns appear 12 more severe (Figure 4c). Groups with 1-2mm of sliding between turns produced high values that 13 diminished in the other groups to near zero for the $100 \mathrm{~mm}$ group. It is important to note that some 14 sliding is required to produce wear-simply rotating the pins ( $0 \mathrm{~mm}$ sliding between turns) produced no 15 measurable wear. In fact, the pins in this group gained weight, typically $0.1 \mathrm{mg}$ over the course of 16 testing. 


\section{Discussion}

The cumulative wear increased proportionally with the number of cross-shear events (i.e. turns) and the results point towards a variable wear rate as the groups with less sliding between turns generated lower wear rates. The total wear amount increases as the number of turns increases-more wear is observed with increasing cycle count (Figure 3)-as long as the pins experience some sliding after the turn. The wear subsequent to a change in direction, however, is not constant as evidenced by the changing values of wear normalized by total sliding distance (Figure 4c). This may indicate a return to 'unidirectional' sliding as hypothesized (recall Figure 1). Furthermore, the data suggests that the transition from a high instantaneous wear rate to a low wear rate occurs very rapidly (less than $5 \mathrm{~mm}$ ).

Conceptually the wear paths used in this investigation represent different size squares, i.e. squares with $1,2,5,10$, and $100 \mathrm{~mm}$ sides. It is important to note that current wear algorithms reported in the literature $[19,22,23]$ do not account for the observed varying wear rate and would incorrectly scale wear results with the overall length of the sliding path. Specifically, they would predict a 20 fold increase in the wear per cycle of the $100 \mathrm{~mm}$ path compared to the $5 \mathrm{~mm}$ path, which is in stark contrast to the nearly uniform results between these groups observed in the current study.

Wear is an important factor in the long-term success of joint arthroplasty. Computer simulations can potentially provide insight into wear performance, but at this time are effective only at qualitative comparisons. The data presented here may improve computational tools and promote quantitative analysis for the design process. Early and ongoing applications in spine [27] and knee [28] have shown promise. Additional work is needed to better understand and apply joint-specific tribological conditions that might further improve the predictive power over direct extrapolations of these pin-on-disk results.

One limitation of the study is the manner that we achieved long sliding distances. In order to attain $100 \mathrm{~mm}$ of sliding we reciprocated the pins $5 \mathrm{~mm}$. We assert that reciprocal motion, without any deviation from linear sliding, does not contribute significantly to wear. This has been borne out in the literature [18-21] as well as internal testing. Specifically, the results in the current study comport with wear rates of these same polyethylene materials when articulated in a square articulation path. When similar GVF and XLK pins were articulated in $10 \mathrm{~mm} \times 10 \mathrm{~mm}$ squares they generated wear rates of $2.10 \pm$ 0.03 and $1.07 \pm 0.07 \mathrm{mg} /$ Mturns, respectively, [29] which compares quite well to the wear rates in this study of $2.40 \pm 0.18$ and $1.13 \pm 0.21 \mathrm{mg} /$ Mturns for the $10 \mathrm{~mm}$ groups of GVF and XLK, respectively. Another limitation is the length of testing. Each test was restricted to a two-week duration with 50 hour testing intervals and a sliding speed of $64 \mathrm{~mm} / \mathrm{sec}$. These constraints provided uniform exposure to serum, which denatures during testing, and limited potential viscoelastic effects from creeping into the results whilst completing the testing matrix in a reasonable amount of time. The cumulative weight loss of all conditions displays linear trends, which offers some evidence for stable wear. Extending testing would be required to strengthen this claim, but several investigators have found that pin on disk investigations have shown stable wear [19, 21, 30, 31]. Additionally, it would have been interesting to evaluate sliding distances smaller than $1 \mathrm{~mm}$, however, this was not feasible for two reasons: (1) limitations on the resolution of the OrthoPOD motion and (2) the expected weight loss would be on the same order as the standard deviations observed in this study and therefore approaching the limit of our 
ability to detect differences (i.e. signal to noise ratio). Lastly, we did not measure surface characteristics at a molecular or macromolecular level and cannot comment on the mechanism of the observed wear phenomenon. Further experimentation and additional techniques are required to capture the transient behavior without introducing artifact.

It is important to note that the reciprocal motion used in this experiment provided a homogenous crossshear condition across the entire pin area during sliding. This is due to the method of articulation. Specifically the orientation of the pin is always parallel to the sliding direction even if it travels on the broad arc. Cross-shear is only introduced after the pin is rotated and articulates in a direction skewed from the previous sliding direction. If the OrthoPOD test machine was used to create square or rectangular motion paths, it would not be able to achieve long sliding distances and it could only accomplish these motions through simultaneous pin translation and rotation leading to heterogeneous cross-shear conditions (as recognized by previous studies [19]). By decoupling the sliding and rotation motions we have avoided these complications.

52 While this study advances the fundamental understanding of polyethylene wear, care should be taken when interpreting and applying these results to other testing conditions. We have applied two different crosslinked polyethylenes in unique sliding motions against cobalt chrome disks in specific environmental surroundings. Other polyethylenes are likely to exhibit similar trends but their exact behavior will depend on their base resin, additives, and extent of crosslinking [19, 32-34]. Also the current study employed only $90^{\circ}$ changes in direction. It is not clear how the smaller changes in direction would affect wear. Intuitively, the wear will decrease monotonically as the change in direction is reduced from $90^{\circ}$ down to $0^{\circ}$; however, the exact relationship is not known and is an area of further exploration. It is also important to note that we tested in $90 \%$ bovine serum supplemented with EDTA and sodium azide. The serum concentration and choice of anti-bacterial agent can significantly influence wear and should be appreciated when comparing results from different laboratories [35-37].

63 In conclusion, we have provided evidence that the wear of moderately crosslinked polyethylene varies

64 along a sliding path, which contrasts to the Archard relationship, which states that wear is linearly 65 related to sliding distance. Our results suggest that the wear after a discrete cross-shear event (ie a change in sliding direction) is higher, but with continued linear the wear rate appears to drop abruptly to near zero-returning to the low wearing condition of unidirectional sliding [18-21]. The data further suggests that this sudden transition occurs less than $5 \mathrm{~mm}$ from the change in direction. The results of this study could aid the development of improved computational tools. Additional studies are required for non-orthogonal articulation paths as well as exploration into the underlying mechanism of wear.

\section{Acknowledgements}

The authors greatly appreciate the technical assistance and input from Michelle Ross, Adam Schlachter,

3 Mark Heldreth, Dan Auger, Lauren Brett, Jennifer Tikka, and Sarah Aust as well as Aaron Winey for his 4 help creating some of the figures. 
$\underline{\text { Tables }}$

\begin{tabular}{ccccc} 
Group & $\begin{array}{c}\text { Reciprocations } \\
\text { per Cycle }\end{array}$ & $\begin{array}{c}\text { Total } \\
\text { Turns }\end{array}$ & $\begin{array}{c}\text { Total } \\
\text { Cycles }\end{array}$ & $\begin{array}{c}\text { Total } \\
\text { Distance }\end{array}$ \\
\hline $0 \mathrm{~mm}$ & $0 \times 0 \mathrm{~mm}$ & $0.60 \mathrm{M}$ & $0.30 \mathrm{M}$ & $0.0 \mathrm{~km}$ \\
$1 \mathrm{~mm}$ & $1 \times 1 \mathrm{~mm}$ & $1.62 \mathrm{M}$ & $0.81 \mathrm{M}$ & $1.6 \mathrm{~km}$ \\
$2 \mathrm{~mm}$ & $1 \times 2 \mathrm{~mm}$ & $1.56 \mathrm{M}$ & $0.78 \mathrm{M}$ & $3.1 \mathrm{~km}$ \\
$5 \mathrm{~mm}$ & $1 \times 5 \mathrm{~mm}$ & $1.44 \mathrm{M}$ & $0.72 \mathrm{M}$ & $7.2 \mathrm{~km}$ \\
$10 \mathrm{~mm}$ & $2 \times 5 \mathrm{~mm}$ & $1.20 \mathrm{M}$ & $0.60 \mathrm{M}$ & $12.0 \mathrm{~km}$ \\
$100 \mathrm{~mm}$ & $20 \times 5 \mathrm{~mm}$ & $0.48 \mathrm{M}$ & $0.24 \mathrm{M}$ & $48.0 \mathrm{~km}$
\end{tabular}

Table 1. Experimental conditions. 
Figures

Figure 1

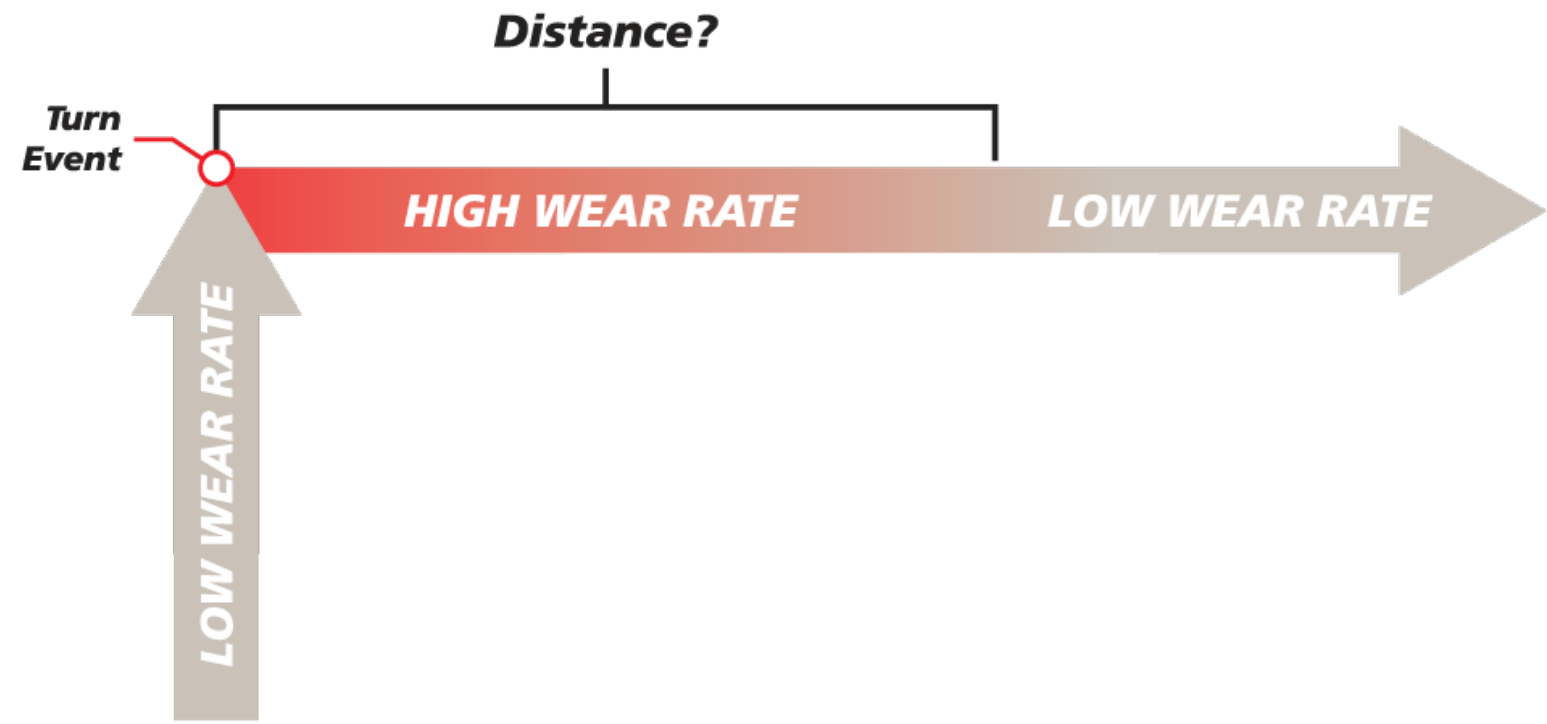


Figure 2

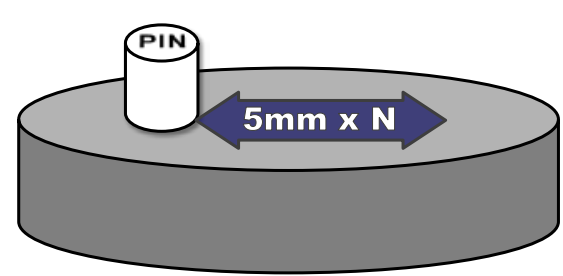

(a)

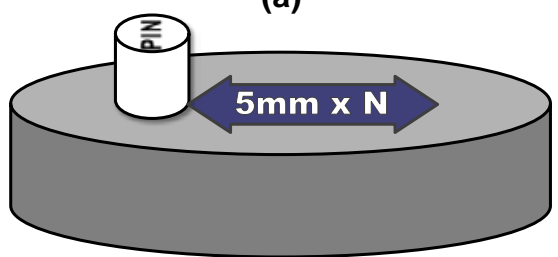

(c)

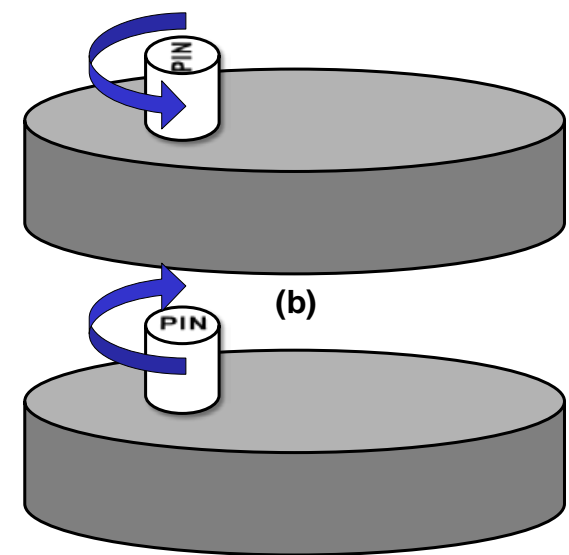

(d) 
Figure 3a

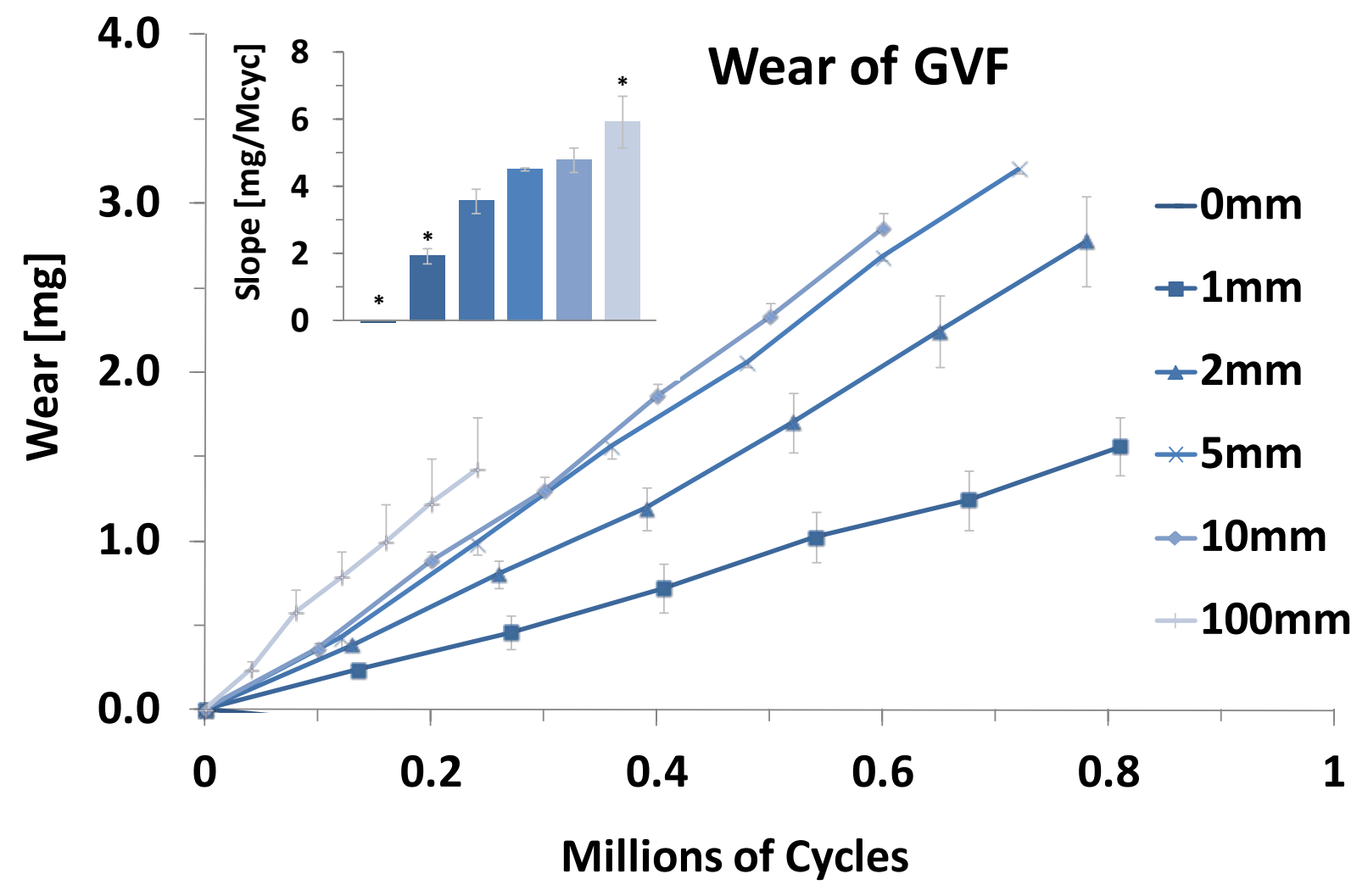


Figure $3 b$

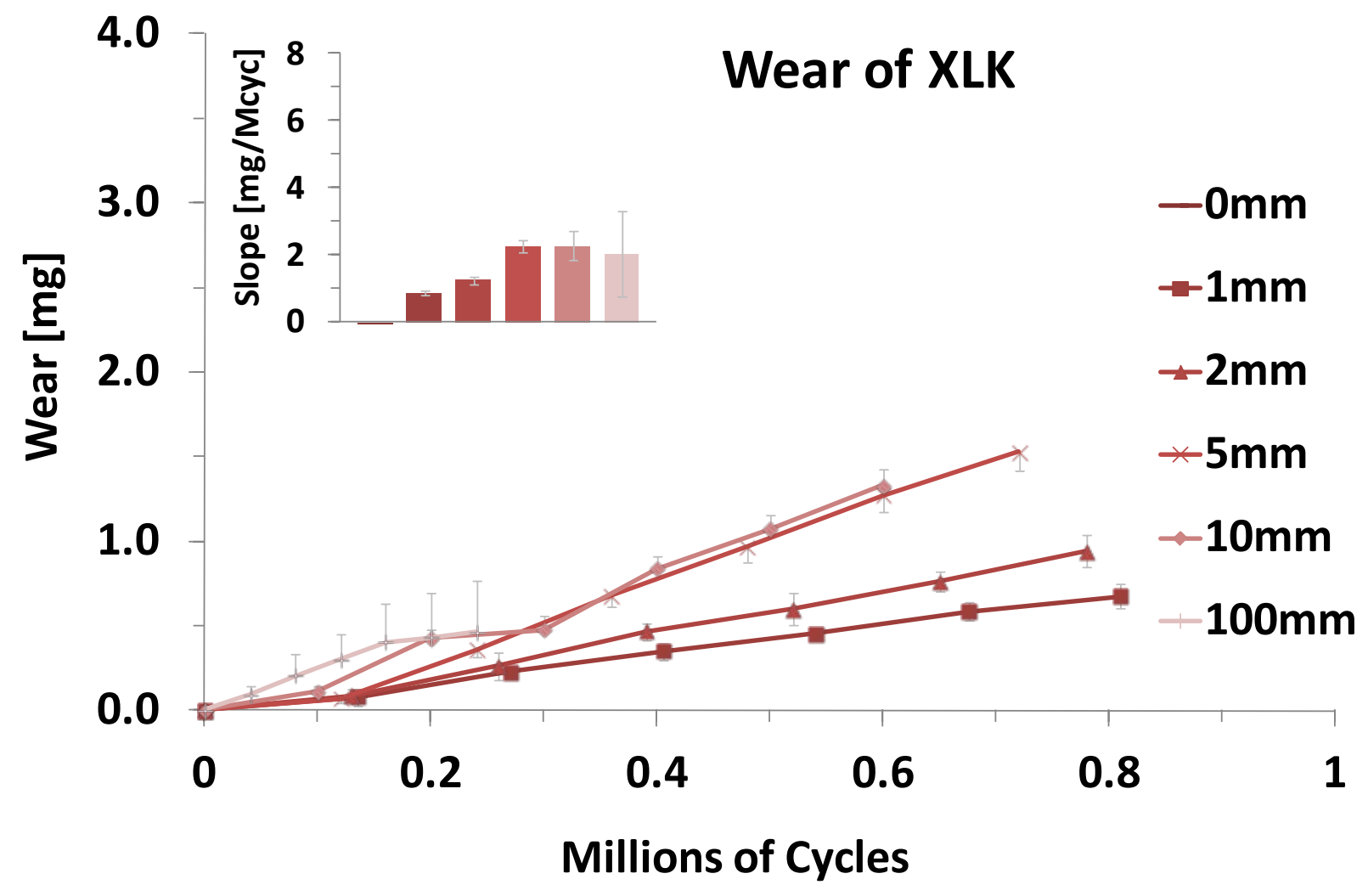


Figure 4a

\section{Wear Rates for Various Sliding Conditions}

$$
\text { GVF } \square \text { XLK }
$$

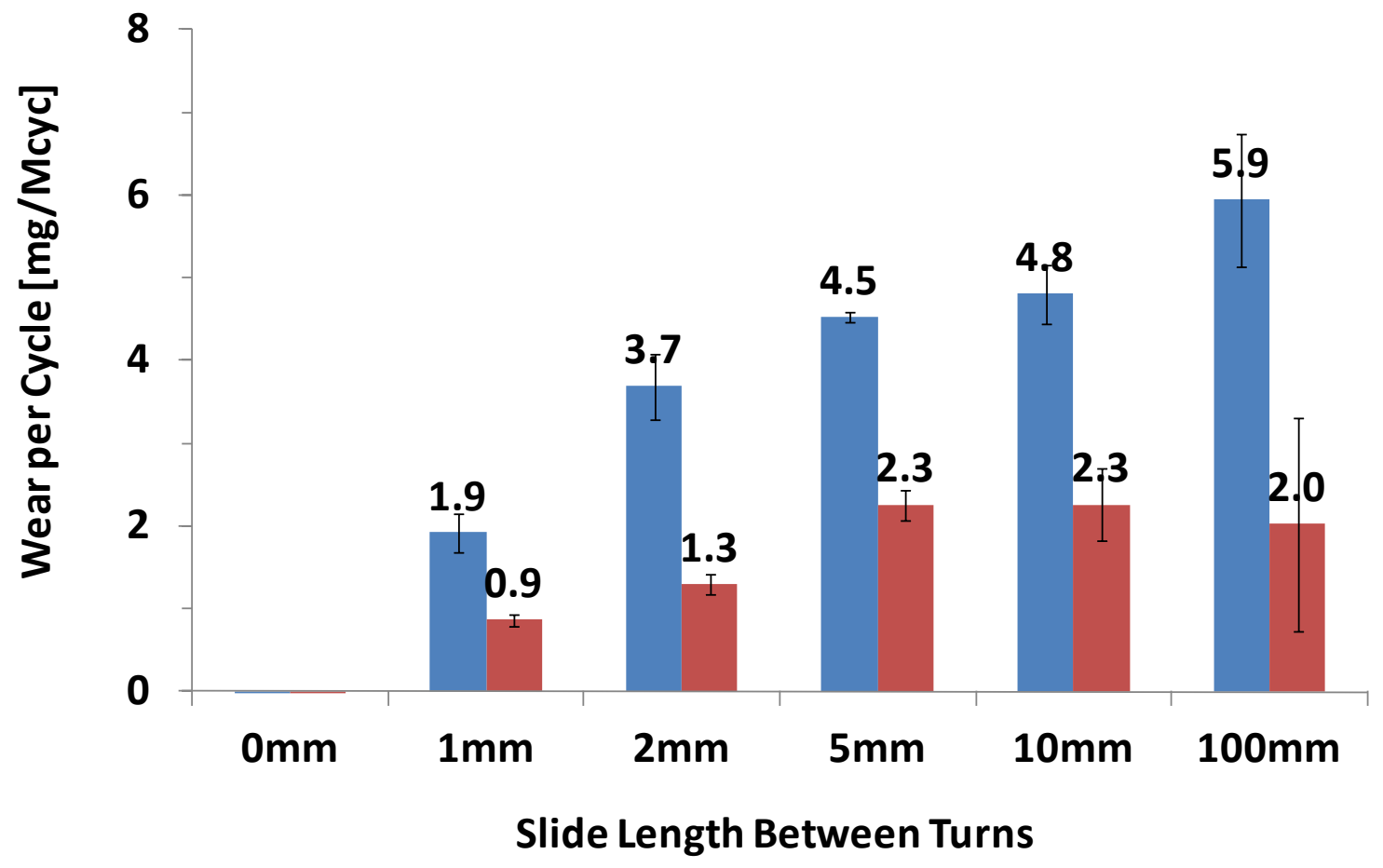




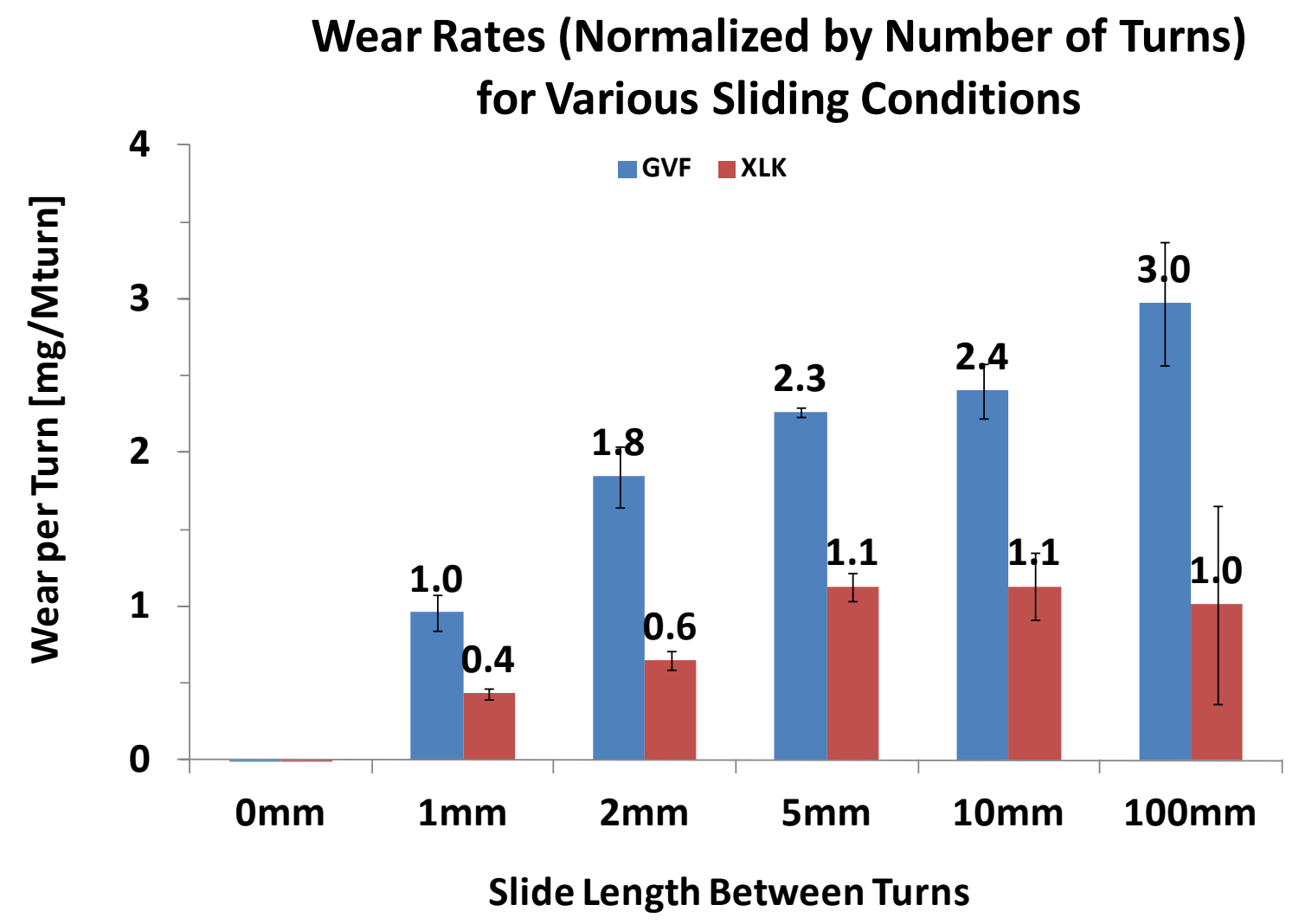


Figure 4c

Wear Normalized by Cumulative Sliding Distance for Various Sliding Conditions

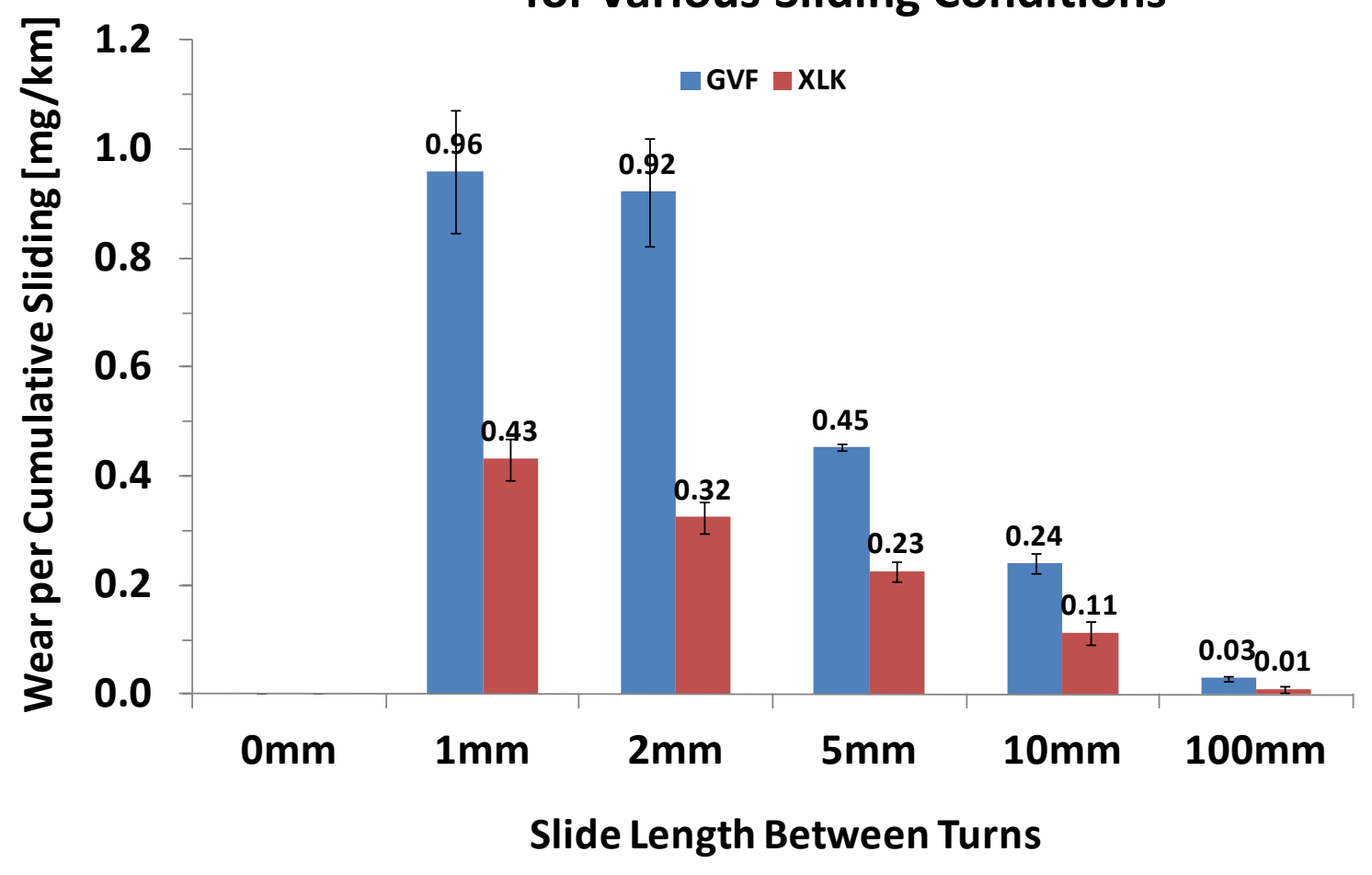




\section{Captions}

Figure 1. A linear wear path that undergoes a sudden change in direction will generate a high instantaneous wear rate initially and then will transition to a near zero instantaneous wear rate with continued sliding. The sliding distance required to achieve the reduced wear rate is unknown.

Figure 2. (a) Pins reciprocated in segments $(1,2,5 \mathrm{~mm})$ under load until they achieved the target sliding distance (eg $5 \mathrm{~mm} \times 20$ ). (b) Pins stopped translating and rotated $90^{\circ}$ under reduced load. (c) The loading was restored and sliding recommenced. (d) Pins rotated to $0^{\circ}$ under reduced load.

Figure 3. Wear of (a) GVF ${ }^{\mathrm{TM}}$ and (b) XLK ${ }^{\mathrm{TM}}$ pins for several sliding conditions (see text for details). Inset shows the average slope for each group. Note: the $0 \mathrm{~mm}$ group exhibited weight gain and is not visible on the graph. Error bars represent standard deviation. Note that the time duration and sliding velocity of each interval was held constant to maintain similar testing conditions; consequently the cycle count per interval for each group was different. Statistical differences within each material (experimentwise $\alpha$ $=0.05)$ are denoted by asterisks $(*)$.

Figure 4. Wear normalized by (a) number of cycles, (b) number of turns, and (c) total sliding distance for the $\mathrm{GVF}^{\mathrm{TM}}$ and $\mathrm{XLK}{ }^{\mathrm{TM}}$ pins under several sliding conditions (see text for details). Note: the $0 \mathrm{~mm}$ group exhibited weight gain and is not visible on the graph. Error bars represent standard deviation. 


\section{$\underline{\text { References }}$}

[1] The burden of musculoskeletal conditions at the start of the new millenium. Geneva: World Health Organization; 2003.

[2] J.J. Callaghan, M.R. O'Rourke, M.F. Iossi, S.S. Liu, D.D. Goetz, D.A. Vittetoe, P.M. Sullivan, R.C. Johnston. Cemented rotating-platform total knee replacement. A concise follow-up, at a minimum of fifteen years, of a previous report. J Bone Joint Surg Am, September 1, 2005;87 (2005) 19951998.

[3] M.C. Dixon, R.R. Brown, D. Parsch, R.D. Scott. Modular fixed-bearing total knee arthroplasty with retention of the posterior cruciate ligament. A study of patients followed for a minimum of fifteen years. J Bone Joint Surg Am, March 1, 2005;87 (2005) 598-603.

[4] S. Kurtz, F. Mowat, K. Ong, N. Chan, E. Lau, M. Halpern. Prevalence of primary and revision total hip and knee arthroplasty in the united states from 1990 through 2002. J Bone Joint Surg Am, July 1, 2005;87 (2005) 1487-1497.

[5] S. Kurtz, K. Ong, E. Lau, F. Mowat, M. Halpern. Projections of primary and revision hip and knee arthroplasty in the united states from 2005 to 2030. J Bone Joint Surg Am, Apr;89 (2007) 780-785.

[6] S. Bauman, D. Williams, D. Petruccelli, W. Elliott, J.D. Beer. Physical activity after total joint replacement: A cross-sectional survey. Clinical Journal of Sport Medicine;17 (2007) 104-108.

[7] W.L. Healy, S. Sharma, B. Schwartz, R. Iorio. Athletic activity after total joint arthroplasty. J Bone Joint Surg Am, October 1, 2008;90 (2008) 2245-2252.

[8] M.A. Mont, D.R. Marker, T.M. Seyler, L.C. Jones, F.R. Kolisek, D.S. Hungerford. High-impact sports after total knee arthroplasty. The Journal of Arthroplasty;23 (2008) 80-84.

[9] E.A. Swanson, T.P. Schmalzried, F.J. Dorey. Activity recommendations after total hip and knee arthroplasty: A survey of the american association for hip and knee surgeons. J Arthroplasty, Sep;24 (2009) 120-126.

[10] B.J. Fregly, W.G. Sawyer, M.K. Harman, S.A. Banks. Computational wear prediction of a total knee replacement from in vivo kinematics. J Biomech, Feb;38 (2005) 305-314.

[11] L.A. Knight, S. Pal, J.C. Coleman, F. Bronson, H. Haider, D.L. Levine, M. Taylor, P.J. Rullkoetter. Comparison of long-term numerical and experimental total knee replacement wear during simulated gait loading. Journal of Biomechanics;40 (2007) 1550-1558.

[12] M.A. Strickland, M. Taylor. In-silico wear prediction for knee replacements--methodology and corroboration. Journal of Biomechanics;42 (2009) 1469-1474.

[13] J.F. Archard. Contact and rubbing of flat surfaces. Journal of Applied Physics;24 (1953) 981-988.

[14] T.A. Maxian, T.D. Brown, D.R. Pedersen, J.J. Callaghan. 3-dimensional sliding/contact computational simulation of total hip wear. Clinical Orthopaedics and Related Research;333 (1996) 41-50.

[15] A.R. Hopkins, U.N. Hansen, A.A. Amis, L. Knight, M. Taylor, O. Levy, S.A. Copeland. Wear in the prosthetic shoulder: Association with design parameters. Journal of Biomechanical Engineering;129 (2007) 223-230.

[16] G. Matsoukas, I.Y. Kim. Design optimization of a total hip prosthesis for wear reduction. Journal of Biomechanical Engineering;131 (2009) 051003-051012.

[17] S. Pal, H. Haider, P.J. Laz, L.A. Knight, P.J. Rullkoetter. Probabilistic computational modeling of total knee replacement wear. Wear;264 (2008) 701-707.

[18] C.R. Bragdon, D.O. O'Connor, J.D. Lowenstein, M. Jasty, S.A. Biggs, W.H. Harris. A new pin-on-disk wear testing method for simulating wear of polyethylene on cobalt-chrome alloy in total hip arthroplasty. The Journal of Arthroplasty;16 (2001) 658-665.

[19] L. Kang, A.L. Galvin, T.D. Brown, Z. Jin, J. Fisher. Quantification of the effect of cross-shear on the wear of conventional and highly cross-linked uhmwpe. J Biomech;41 (2008) 340-346. 
[20] V. Saikko, O. Calonius, J. Keränen. Effect of slide track shape on the wear of ultra-high molecular weight polyethylene in a pin-on-disk wear simulation of total hip prosthesis. Journal of Biomedical Materials Research Part B: Applied Biomaterials;69B (2004) 141-148.

[21] M. Turell, A. Wang, A. Bellare. Quantification of the effect of cross-path motion on the wear rate of ultra-high molecular weight polyethylene. Wear;255 (2003) 1034-1039.

[22] M.A. Hamilton, M.C. Sucec, B.J. Fregly, S.A. Banks, W.G. Sawyer. Quantifying multidirectional sliding motions in total knee replacements. Journal of Tribology;127 (2005) 280-286.

[23] A. Wang. A unified theory of wear for ultra-high molecular weight polyethylene in multi-directional sliding. Wear;248 (2001) 38-47.

[24] L.A. Knight, A.L. Galvin, J. Jeffers, A. Hopkins, J. Fisher, M. Taylor. Influence of cross-shear on the wear of polyethylene: A finite element study. Transactions of the Orthopaedic Research Society; 2005; Washington D.C.; 2005. p. 0987.

[25] Implants for surgery -- wear of total knee-joint prosteheses -- part 2: Methods of measurement: ISO; 2000.

[26] F732 standard test method for wear testing of polymeric materials used in total joint prostheses: ASTM; 2006.

[27] J.R. Armstrong, P.J. Laz, P.J. Rullkoetter, A.J. Petrella. A modified form of the archard wear law to account for cross-shear. Orthopaedic Research Society; 2010; New Orleans; 2010.

[28] M.A. Strickland, M.R. Dressler, M. Taylor. Third-generation uhmwpe wear algorithms: Theory and application. World Conference of Biomechanics; 2010; Singapore; 2010.

[29] R. King, V.S. Narayan, C. Ernsberger, M. Hanes. Characterization of gamma-irradiated uhmwpe stabilized with a hindered-phenol antioxidant. Transactions of the Orthopaedic Research Society; 2009; Las Vegas, NV; 2009. p. 0019.

[30] D. Mazzucco, M. Spector. Effects of contact area and stress on the volumetric wear of ultrahigh molecular weight polyethylene. Wear;254 (2003) 514-522.

[31] V. Saikko. Performance analysis of an orthopaedic biomaterial 100-station wear test system. Proceedings of the Institution of Mechanical Engineers, Part C: Journal of Mechanical Engineering Science;224 (2010) 697-701.

[32] S.M. Kurtz. Uhmwpe biomaterials handbook. 2nd ed. New York: Elsevier, 2009.

[33] H. McKellop, F.-w. Shen, B. Lu, P. Campbell, R. Salovey. Development of an extremely wearresistant ultra high molecular weight polythylene for total hip replacements. Journal of Orthopaedic Research;17 (1999) 157-167.

[34] O.K. Muratoglu, C.R. Bragdon, D.O. O'Connor, M. Jasty, W.H. Harris, R. Gul, F. McGarry. Unified wear model for highly crosslinked ultra-high molecular weight polyethylenes (uhmwpe). Biomaterials;20 (1999) 1463-1470.

[35] C. Kaddick, M.A. Wimmer. Hip simulator wear testing according to the newly introduced standard iso 14242. Proceedings of the Institution of Mechanical Engineers, Part H: Journal of Engineering in Medicine;215 (2001) 429-442.

[36] T. Schwenke, C. Kaddick, E. Schneider, M.A. Wimmer. Fluid composition impacts standardized testing protocols in ultrahigh molecular weight polyethylene knee wear testing. Proc Inst Mech Eng [H], Nov;219 (2005) 457-464.

[37] Y.S. Liao, P.D. Benya, H.A. McKellop. Effect of protein lubrication on the wear properties of materials for prosthetic joints. Journal of biomedical materials research;48 (1999) 465-473. 